Daimon. Revista Internacional de Filosofía, Suplemento 5 (2016), 163-174

ISSN: 1130-0507 (papel) y 1989-4651 (electrónico)

http://dx.doi.org/10.6018/daimon/268731

\title{
Cuerpo, conciencia y voluntad en Nietzsche
}

\author{
Body, Consciousness and Will in Nietzsche
}

PEDRO A. VIÑUELA VILLA*

\begin{abstract}
Resumen: En contra de la corriente predominante de la filosofía moderna que ha pretendido hacer del yo, la conciencia y la voluntad libre los puntales del pensamiento, el conocimiento y la praxis racional, Nietzsche propugna la rehabilitación del cuerpo, en general marginado por dicha tradición, situándolo en el centro de la escena filosófica como el auténtico "sí-mismo" (Selbst). En el presente artículo se exponen algunos puntos relevantes sobre la concepción que Nietzsche defiende del cuerpo en relación con su filosofía de la voluntad de poder.
\end{abstract}

Palabras clave: cuerpo, yo, conciencia, inconsciente, voluntad, poder.

\begin{abstract}
Modern philosophy has placed the self, the consciousness and the free will as the cornerstones of thought, knowledge and rational praxis. Against this position, Nietzsche reinstates the body, in general relegated in that tradition, in order to place it in the focus of the philosophical scene as the true "self" (Selbst). In this paper, thus, I will examine some important points concerning Nietzsche's view on body in relation to his philosophy of the will to power.
\end{abstract}

Keywords: body, self, consciousness, unconscious, will, power.

El cuerpo creador se creó para sí el espíritu como una mano de su voluntad.

Nietzsche, Así habló Zaratustra.

\section{Introducción}

La filosofía moderna, como se sabe, ha pretendido fundar el saber sobre las bases monolíticas de la conciencia y del yo pensante. Así, en el albor del pensamiento moderno, Descartes afirma como la primera verdad de su sistema filosófico el cogito ergo sum, en virtud del cual se establece como certeza absoluta la existencia del sujeto que duda a partir de la constatación absolutamente evidente e indubitable que el pensamiento consciente hace de su

Fecha de recepción: 12/06/2016. Fecha de aceptación: 20/07/2016.

* Licenciado en Filosofía, Doctor en Filosofía e Ingeniero Industrial. Profesor Asociado en la Universidad Internacional de La Rioja (UNIR). Correo electrónico: pedro.vinuela@unir.net. Principales líneas actuales de investigación: filosofía moderna (Kant, Leibniz, Descartes, Nietzsche), filosofía de las matemáticas, filosofía del lenguaje y de la percepción. Cabe mencionar como publicaciones recientes: Viñuela, P. (2016), «Perception, Presumption and Perspectivism in Leibniz», en: W. Li (ed.): “Für unser Glück oder das Glück anderer". Vorträge des X. Internationalen Leibniz-Kongresses (Band IV), Hildesheim: Georg Olms Verlag, pp. 335-348; Viñuela. P. (2016). «Lenguaje e investigación de conceptos: Kant sobre la metodología de la filosofía», en: J. M. Navarro Cordón, R. Orden Jiménez y R. Rovira (eds.): Nuevas perspectivas sobre la filosofía de Kant, Madrid: Escolar y Mayo Editores, pp. 119-126. 
propio ser como actividad pensante, es decir, ego sum cogitans. De hecho, según Spinoza, el ego cogito es el axioma absoluto y primero del edificio del saber que Descartes busca fundar ${ }^{1}$. Y Kant, a pesar de sus críticas a Descartes, se mantiene en lo esencial dentro de los postulados cartesianos asignando a la autoconciencia un papel básico en la constitución de la experiencia objetiva y en la fundamentación del saber. De este modo, en la filosofía crítica la unidad sintética originaria de apercepción es condición necesaria de todo uso del entendimiento, es decir, de todo pensar. Y aunque Kant asevera contra Descartes que el yo pienso no suministra conocimiento alguno, argumenta que es condición de posibilidad de toda experiencia en cuanto representación general de la autoconciencia (Selbstbewußtsein) y como proposición formal de la apercepción (Apperzeption), puesto que expresa la percepción de sí mismo (Wahrnehmung seiner selbst) ${ }^{2}$.

Ahora bien, como se puede ver, ni el yo pienso cartesiano ni el sujeto trascendental kantiano remiten en primera instancia a la dimensión corporal del sujeto. La subjetividad así concebida se muestra desconectada de la corporalidad, ya sea por razones metodológicas inherentes a dichas filosofías, ya sea porque, en última instancia, el cuerpo es considerado en realidad una limitación e impedimento empírico más que una condición trascendental de posibilidad.

Nietzsche toma posición ante este planteamiento, invirtiendo el punto de partida y afirmando la primacía del cuerpo, puesto que, en su opinión, es algo mucho más sorprendente e importante que la conciencia y el espíritu. En efecto, oponiéndose a gran parte de la tradición filosófica moderna que ha querido hacer, como hemos mencionado, de la conciencia y del yo pensante el fundamento del saber y -en tanto que el yo es contemplado como sujeto práctico, dotado de una voluntad libre y autónoma- el fundamento de la moral, Nietzsche hace una revalorización a fondo del cuerpo como contexto en el que se manifiesta el núcleo esencial de su doctrina de la voluntad de poder, de modo que el cuerpo pasa a constituir el escenario privilegiado en el que comparece la pluralidad, la complejidad y la abundancia de la vida como lucha incesante de los instintos por someterse unos a otros.

Según Nietzsche, no es casual que, en su gran mayoría, los filósofos se hayan mostrado hostiles con el cuerpo, despreciándolo al igual que a los sentidos, ya que se muestra reacio a la lógica y la razón ${ }^{3}$ :

1 En este sentido, Husserl (1992, 9), en sus Meditaciones cartesianas, sostiene que para Descartes el axioma de la absoluta autocerteza del yo, con sus principios axiomáticos innatos, tiene un papel similar respecto a la ciencia universal al que tienen los axiomas geométricos en la geometría, aunque ese fundamento axiomático se sitúe en un estrato aún más profundo. Y Heidegger (1975, 75-83) afirma que el cogito, dentro del proyecto matemáticoaxiomático cartesiano, es el intento de establecer el yo del yo pienso como el principio supremo normativo del saber y de las determinaciones del ser.

2 Cf. KrV, A 343/B 401, A 354. La proposición "yo pienso", según Kant, no es una experiencia sino "la forma de la apercepción que inhiere y precede a toda experiencia" (KrV, A 354).

3 En todo caso, la filosofía contemporánea se ha interesado por el cuerpo, aunque no necesariamente desde el punto de vista nietzscheano. Cabe destacar el interés de la fenomenología (en especial Husserl y MerleauPonty) por el análisis del cuerpo (siendo esencial la distinción fenomenológica entre Leib y Körper), lo cual ha terminado repercutiendo, de manera muy significativa, en el enfoque de la psicología cognitiva conocido como "embodied cognition". Ortega también ha reconocido la importancia de la corporalidad: "El hombre es, pues, ante todo, alguien que está en un cuerpo y que en este sentido -repárese, sólo en este sentido- sólo es su cuerpo. Y este simple pero irremediable hecho va a decidir la estructura concreta de nuestro mundo y, con ello, de nuestra vida y destino" (Ortega y Gasset, 2013, 81). 
¡Ser filósofo, ser momia, representar el monótono-teísmo con una mímica de sepulturero! - ¡Y, sobre todo, fuera el cuerpo, esa lamentable idée fixe [idea fija] de los sentidos!, ; sujeto a todos los errores de la lógica que existen, refutado, incluso imposible, aun cuando es lo bastante insolente para comportarse como si fuera real! ${ }^{4}$

El cuerpo es para Nietzsche, en cambio, "la gran razón" y "el gran dominador", de modo que en Así habló Zaratustra es proclamado como soberano poderoso y sabio desconocido, del cual el yo y el espíritu son meros instrumentos a su servicio ${ }^{5}$. De ahí que, habiendo sido negado, marginado y subestimado, Nietzsche quiera recuperar el cuerpo para la filosofía, devolviéndole su condición de "centro de gravedad" del hombre, ya que constituye el lugar central en el que la historia ha quedado grabada de manera más radical y honda que en la memoria y en el conocimiento teórico de la humanidad ${ }^{6}$.

En oposición, por tanto, a aquellos que pretenden hacer del yo, la conciencia y la voluntad libre el fundamento primero de todo pensamiento filosófico riguroso, Nietzsche se propone trastocar la jerarquización valorativa en la que descansa esa tergiversación, afirmada, una y otra vez, acríticamente por la filosofía tradicional, restableciendo el cuerpo al puesto que, desde el punto de vista genealógico del valor, siempre debería ocupar. Reinterpretado correctamente desde una óptica más radical, Nietzsche pretende convertir el cuerpo en clave exegética que le permita alcanzar una mejor comprensión del hombre y del devenir. Pues en el cuerpo se manifiesta la sabiduría inconsciente de la vida, una sabiduría no reflexiva ni lógica que es anterior y más sustantiva que el saber consciente y científico, el cual no es, después de todo, más que secundario, ya que se mueve en un plano mucho más superficial de la existencia. En efecto, interpretado como physis, "el cuerpo es dinámica de fuerzas de una mayor sutileza e inteligencia. Tiene la seguridad innata de un funcionamiento automático y una sabiduría que está por encima de nuestro saber consciente, y que hace de lo corporal, en cierto modo, «una conciencia de rango superior al yo»"7.

De todos modos, y a pesar de que la corriente central del pensamiento moderno ha seguido el derrotero que, desde la perspectiva exegética de Nietzsche, se revela, a la postre, como meramente ilusorio, es preciso subrayar que Spinoza ya había vislumbrado en parte la relevancia del problema del cuerpo, al advertir que ignoramos de qué es realmente capaz (quid corpus possit), es decir, qué es lo que puede o no puede hacer un cuerpo a partir de las meras leyes de la naturaleza, en cuanto es considerada sólo como corpórea, sin ser determinado por el alma ${ }^{8}$.

4 CI, La "razón" en la filosofía/Nietzsche, 2002, 52.

$5 Z$ Za., De los despreciadores del cuerpo/Nietzsche, 2008a, 64-65.

6 Vid. Jara, 1998, 52-53.

7 Sánchez Meca, 2002, 108.

8 Ética, III, 2 escolio/Spinoza, 2014, 108. Concluye Spinoza este párrafo del siguiente modo: "De donde se sigue que cuando los hombres dicen que tal o cual acción del cuerpo nace del alma, que tiene imperio sobre el cuerpo, no saben lo que dicen, ni hacen otra cosa que confesar en palabras especiosas que ignoran, sin admirarse de ello, la verdadera causa de aquella noción" (Ética, III, 2 escolio/Spinoza, 2014, 108). 


\section{El cuerpo y la conciencia}

Nietzsche, por tanto, utiliza el cuerpo como filum Ariadnes para repensar a fondo lo que hasta ahora sólo ha sido pensado de manera superficial. Al hacerlo, como veremos más adelante, fragmenta el sujeto unitario autofundante del pensamiento moderno en una multiplicidad de fuerzas antagónicas, concibiendo el cuerpo como paradigma hermenéutico a la luz del cual ha de leerse la hipótesis de la voluntad de poder. Desde esta perspectiva, la conciencia se presenta como algo totalmente sobredimensionado y sobreestimado, de modo que la identificación moderna de pensamiento en general con pensamiento consciente se revela, a la postre, como mera ilusión.

Durante mucho tiempo se ha considerado al pensar consciente como el pensamiento en general. Sólo ahora alborea en nosotros la verdad: la parte más grande de nuestra acción espiritual transcurre de un modo inconsciente, imperceptible 9 .

La conciencia ha sido malinterpretada como lo eterno, lo último y lo más originario del hombre. Sin embargo, siendo lo más débil, imperfecto y postrero del desarrollo de lo orgánico, si la subsistencia del género humano hubiese dependido de la conciencia, la humanidad habría desaparecido hace tiempo de la faz de la Tierra de no ser por la acción asociativa y conservadora de los instintos ${ }^{10}$.

En todo caso, ya Leibniz había llamado la atención sobre lo equivocado de pretender atribuir una importancia y alcance desmesurados al pensamiento consciente. De hecho, es bien sabido que Leibniz fue muy crítico con la concepción cartesiana de la mente, que pretendía hacer del pensamiento consciente la marca distintiva del pensamiento en general ${ }^{11}$. Leibniz, en cambio, defendió y fundamentó la existencia de estados mentales inconscientes. Según su célebre doctrina de las petites perceptions, existen percepciones, pensamientos e incluso apetitos de los que no somos conscientes y que aun así determinan en medida notable cómo pensamos y obramos ${ }^{12}$. La mente, a juicio de Leibniz, siempre piensa, pero en su mayor parte lo hace de manera inconsciente, sin reflexión y sin apercibirse de ello. Este hallazgo notable es subrayado y alabado expresamente por Nietzsche. En La ciencia jovial destaca que Leibniz fue un auténtico pionero al sospechar que son la fisiología y la historia natural las llamadas a plantear correctamente el problema de la conciencia, poniendo de relieve con ello precisamente "cuánto podemos hacer prescindiendo de ella". Podríamos, en efecto, pensar, sentir, querer e incluso "actuar" en el sentido pleno

9 La ciencia jovial, libro IV, 333/Nietzsche, 2010, 521.

10 La ciencia jovial, libro I, 11/Nietzsche, 2010, 344-345.

11 Descartes, Locke y los cartesianos en general.

12 En el prefacio de los Nuevos ensayos sobre el entendimiento humano Leibniz afirma que "hay signos a millares que hacen pensar que en todo momento existen en nosotros infinidad de percepciones, pero sin apercepción y sin reflexión, es decir, cambios en el alma misma de los cuales no nos damos cuenta, porque las impresiones son o demasiado pequeñas al par que excesivas en número, o están demasiado juntas, de manera que no tienen nada que permita distinguirlas por separado, pero aunque estén unidas a las otras no por ello dejan de producir efecto y de hacerse notar en el conjunto, aunque sea confusamente" (Leibniz, 1977, 46). 
del término, sin que nada de eso necesitara entrar en nuestra conciencia. Por eso Nietzsche afirma que toda la vida sería posible sin que tuviese que verse en el espejo, revelándose así el carácter básicamente superfluo de la conciencia ${ }^{13}$.

Es más, según Leibniz, la zona de percepción clara en la que se mueve la conciencia está limitada y condicionada por el hecho de que cada mónada tiene un cuerpo que le pertenece y sobre el cual ejerce su dominio, de modo que a través de $s u$ cuerpo la mónada se representa todo el universo. Mientras que su representación es confusa en el detalle de casi la totalidad del cosmos, la mónada se representa de manera distinta sólo una porción muy pequeña de las $\operatorname{cosas}^{14}$. Por lo demás, el cuerpo orgánico del ser vivo no es en realidad una unidad simple, sino una organización viviente compuesta por una multiplicidad de mónadas, aunque domine solamente una. Como señala Deleuze, "una mónada tiene como propiedad, no un atributo abstracto, movimiento, elasticidad, plasticidad, sino otras mónadas, como una célula, otras células, o un átomo, otros átomos. Son fenómenos de subyugación, de dominación, de apropiación que satisfacen el dominio de tener, y éste siempre está bajo una cierta potencia"15. Es precisamente por esto que Nietzsche, según Deleuze, se sentirá tan próximo a Leibniz.

En lo que concierne, por otro lado, al origen de la conciencia en el hombre, Nietzsche lo sitúa en el impulso comunicativo y el uso del lenguaje, inherentemente humanos. Según Nietzsche, la sutileza y la fuerza de la conciencia siempre están estrechamente ligadas a la capacidad de comunicación y, sobre todo, a la necesidad de comunicación.

El hombre, como toda criatura viviente, piensa continuamente, pero no tiene conocimiento de ello; el pensar que llega a hacerse consciente sólo es la parte más pequeña de él: la parte más superficial, la peor -pues sólo este pensar consciente sucede mediante palabras, es decir, mediante signos de comunicación, lo que revela la procedencia misma de la conciencia. Por decirlo en pocas palabras: el desarrollo del lenguaje y el desarrollo de la conciencia (no de la razón, sino sólo del llegar-a-serconsciente-de-sí de la razón) van de la mano ${ }^{16}$.

De esta manera, la conciencia no pertenece propiamente a la existencia individual del hombre, sino más bien a su dimensión comunitaria y gregaria. La conciencia sólo se desarrolla sutilmente en relación con lo que es útil para la comunidad y el rebaño, de modo que sólo como animal social el hombre aprendió a ser consciente de sí $^{17}$.

13 Cf. La ciencia jovial, 354/Nietzsche, 2010, 549-550. Más recientemente autores como Schaeffer se aproximan en alguna medida al punto de vista nietzscheano: "La pregunta por los estados conscientes no tiene la importancia que le otorgamos. O más bien, tal vez sea central para nosotros que preguntamos, pero en el "orden de las cosas" por las que se pregunta no es más que un asunto local y circunscrito. Después de todo, los estados de conciencia son sólo una característica intermitente de algunas raras especies de seres vivos: el número de especies que prescinden perfectamente de los estados de conciencia es infinitamente mayor. Dicho de otro modo: si nos tomamos en serio la inversión de perspectiva propuesta aquí, entonces la pregunta por la conciencia no sólo deja de ser fundamental sino que además carece de valor dramático que inevitablemente adquiere en la propuesta fundamentadora, donde debe sostener el conjunto de la arquitectura cognitiva" (Schaeffer, 2009, 340).

14 Cf. Monadología, $\S \S 60-62$.

15 Deleuze, 1989, 141.

16 La ciencia jovial, libro V, 354/Nietzsche, 2010, 551.

17 La ciencia jovial, libro V, 354/Nietzsche, 2010, 550-551. 
En consecuencia, el lugar central que la filosofía ha asignado al sujeto autoconsciente y autofundante ha de ser ocupado por el cuerpo, que es lo que se halla, a la postre, realmente detrás de pensamientos y sentimientos, del sentido y del espíritu ${ }^{18}$. El cuerpo es el genuino "sí-mismo" (Selbst), no el yo (Ich) ni la conciencia. El yo, como advierte Nietzsche en el Crepúsculo de los ídolos, "ha dejado totalmente de pensar, de sentir y de querer"19. Esto se debe a que es en el cuerpo donde acontece la verdadera lucha de fuerzas e instintos inconscientes que, en su mutua y distintiva dominación, dan como resultado lo que la conciencia a veces logra atisbar y cree ilusoriamente poder decidir y conducir. Como indica Sánchez Meca, "los impulsos son siempre juicios incorporados, o sea, forman parte constituyente de nuestro cuerpo y de su vida instintual. Frente a nuestros instintos y la unidad de nuestra dinámica viviente, la conciencia constituye una instancia superficial. El yo no es más que una simplificación lógica y abstracta, la reconversión de la unidad viviente en unidad pensada" 20 .

Por consiguiente, en tanto que la conciencia se muestra superflua para la vida, la pretensión de situar en ella el fundamento filosófico primero parece en cierto modo un contrasentido. Este espejismo sólo cabe entenderlo a la luz del predominio de ciertos instintos que se ha traducido en ficciones como el yo y la voluntad libre para ejercer, a través de ellas, su dominación conforme a sus propias exigencias e intereses.

\section{El cuerpo y la voluntad}

Ahora bien, el hecho de que Nietzsche haya desplazado la conciencia del centro de la atención filosófica, situando en su lugar el cuerpo, no implica que sustente una postura puramente fisiológica y biologicista. La perspectiva nietzscheana es más bien "la de un realismo genealógico de la fuerza o la de una física reflexiva del placer y del dolor que acompañan al ejercicio del crecimiento o del debilitamiento de la fuerza"21. En Nietzsche el interés por el cuerpo constituye la base para una interpretación y una crítica de la cultura que hace de la voluntad de poder la clave hermenéutica principal. Para Nietzsche, en contraste con el punto de vista del positivismo mecanicista de la fisiología científica, "el cuerpo no es un artefacto ni un máquina regidas por las leyes de la mecánica. Es, ante todo, physis, vida, automotricidad ligada al movimiento universal del mundo e inserta en la totalidad dinámica de lo orgánico"22.

En este sentido, el cuerpo, en cuanto punto de partida de la exégesis nietzscheana, constituye el acceso primario a una mejor comprensión del fenómeno de la vida, que la hipótesis de la voluntad de poder expresa esencialmente. Nietzsche tiene un interés hermenéutico-metodológico en el cuerpo, ya que expresa de suyo una configuración múltiple y jerárquica de fuerzas en relaciones de mutua dominación y subordinación. Es más, hacer del cuerpo el "hilo conductor" de la investigación supone intentar desentrañar la lógica de la voluntad de poder para revelar, en base a la experiencia de la vida a través

18 Vid. Za., De los despreciadores del cuerpo/Nietzsche, 2008a, 64-65.

19 CI, Los cuatro grandes errores, 3/Nietzsche, 2002, 70.

20 Sánchez Meca, 2002, 114.

21 Sánchez Meca, 2002, 107-108.

22 Sánchez Meca, 2002, 108. 
del propio cuerpo, el devenir de la apariencia como lucha incesante por la dominación, siguiendo el modelo del querer ${ }^{23}$. El cuerpo humano nos ofrece, en consecuencia, las realidades más básicas y la infraestructura pulsional y valorativa en la que descansa la vida consciente ${ }^{24}$. La hermenéutica genealógica de Nietzsche muestra, por tanto, que hay un vínculo genealógico entre el cuerpo y la cultura, así como una influencia configuradora de la cultura sobre el cuerpo ${ }^{25}$.

El desplazamiento, por tanto, del foco del interés filosófico desde la conciencia al cuerpo, implica situar en primer plano el fenómeno de la voluntad. Pero así como el yo y la conciencia se revelan como ficciones, como fábulas o juegos de palabras, es decir, como productos de una errónea comprensión, la voluntad también ha sido malinterpretada, dando lugar a mitos y tergiversaciones. "El «mundo interno»-afirma Nietzsche en el Crepúsculo de los ídolos- está lleno de fantasmas y de fuegos fatuos: la voluntad es uno de ellos" 26 . Algunos filósofos han efectuado, de hecho, una mala lectura de la voluntad como algo unitario y como la cosa más conocida del mundo. En El mundo como voluntad y representación Schopenhauer sostiene que el mundo fenoménico es ilusorio y que es la voluntad el aspecto más profundo, más real, de nuestro ser. La voluntad no constituye una verdad científica fundada en el conocimiento intelectivo, sino que es "la verdad filosófica por excelencia". La voluntad es la "cosa en sî" de Kant, es la verdadera y única realidad de todo el mundo. Es, en definitiva, según Schopenhauer, el ser en sí de todas las cosas ${ }^{27}$.

Según Nietzsche, el error básico de Schopenhauer consiste en pensar que hay algo así como un querer puro, que sería más puro cuanto más completamente indeterminado se deje lo querido y más decididamente se excluya al que quiere ${ }^{28}$. Nietzsche defiende, en cambio, la hipótesis de la voluntad como pluralidad, pues la supuesta unidad de la voluntad no es más que nominal. Toda volición es en realidad algo complejo y múltiple para lo cual el pueblo no tiene más que una sola palabra ${ }^{29}$. Aquí como casi siempre los filósofos, según Nietzsche, han pecado de exagerar los prejuicios del vulgo. La voluntad no es, en efecto, una entidad simple, sino un complejo de sentir, de pensar y, sobre todo, de afecto de mando (Affekt des Commando's) ${ }^{30}$. Toda volición consiste sencillamente en mandar y obedecer. Pero ¿qué significa mandar? Mandar implica de suyo obedecerse: "un hombre que realiza una volición - es alguien que da una orden a algo que hay en él, lo cual obedece, o él cree que obedece" ${ }^{31}$. Y esto es lo que nos muestra una correcta interpretación de lo que experimentamos en nuestro propio cuerpo. De ahí que la voluntad sea, "en tanto

23 Como señala Heidegger, "el querer mismo es el dominar sobre..., que se extiende más allá de sí; la voluntad es en sí misma poder. Y poder es el querer en-sí-constante. La voluntad es poder y el poder es voluntad" (Heidegger, 2013, 49).

24 Cf. Conill, 2007, 116.

25 Véase Sánchez Meca, 2009, 147.

26 CI, Los cuatro grandes errores, 3/Nietzsche, 2002, 70.

27 Véase El mundo como voluntad y representación, volumen II, libro II, capítulo 28 (Caracterización de la voluntad de vivir)/Schopenhauer, 2010, 461-475.

28 Cf. Heidegger, 2013, 48.

$29 M B M, \S 19 /$ Nietzsche, $2008 \mathrm{~b}, 42$.

30 Cf. $M B M, \S 19 /$ Nietzsche, 2008a, 42.

$31 M B M, \S 19 /$ Nietzsche, 2008b, 42. 
afecto del mando, el signo distintivo de la autoridad y de la fuerza" ${ }^{32}$. Por lo tanto, en el fenómeno del mando comparece una correlación de fuerzas que pone de manifiesto que la voluntad no puede considerarse una unidad simple, uniforme y estática, sino como una estructura social de muchas almas (Gesellschaftsbau vieler Seelen).

\section{El cuerpo como pluralidad}

El cuerpo, como la volición, es también un fenómeno múltiple, ya que se compone de una pluralidad de fuerzas irreductibles. En Así habló Zaratustra Nietzsche declara: "El cuerpo es una gran razón, una pluralidad dotada de un único sentido, una guerra y una paz, un rebaño y un pastor" ${ }^{33}$. La unidad del cuerpo es, como señala Deleuze, ${ }^{34}$ una "unidad de dominación", en la que se da una relación entre fuerzas activas (fuerzas superiores) y fuerzas reactivas (fuerzas inferiores). Precisamente lo que resulta decisivo en el cuerpo es esta proporción entre fuerzas dominantes y fuerzas dominadas. Y como las fuerzas activas escapan, por naturaleza, a la conciencia, la "gran actividad principal es inconsciente", es decir, no sabemos de qué actividad es capaz un cuerpo, puesto que la conciencia es esencialmente reactiva ${ }^{35}$.

Desde esta perspectiva, Nietzsche apuesta por una concepción de la libertad como dominación fisiológica de los instintos superiores sobre los débiles, de modo que el ejercicio efectivo del mando en el cuerpo se rige por el instinto gobernante. Considerado como un campo agonístico de fuerzas que aspiran al sometimiento, se despliega como una pugna permanente conforme a las condiciones y necesidades de la existencia. De ahí que el concepto cristiano de voluntad libre, basado en una supuesta indiferencia de actuar de una forma u otra, no sea más que una mera ficción ${ }^{36}$. Libertad significa, por el contrario, "tener voluntad de autorresponsabilidad". Implica que "los instintos viriles, los instintos que disfrutan con la guerra y la victoria, dominen otros instintos, por ejemplo a los de la «felicidad»"37. La libertad es "algo que se tiene y no se tiene, que se quiere, que se conquista" 38 . La autorresponsabilidad individual se centra, en consecuencia, en una experiencia intrínsecamente agonística, ya que supone una resistencia constante a la institucionalización de la libertad ${ }^{39}$.

32 La ciencia jovial, libro IV, 347/Nietzsche, 2010, 542.

$33 Z a$, De los despreciadores del cuerpo/Nietzsche, 2008a, 64.

34 Deleuze, 1986, 60-62.

35 Cf. Deleuze, 1986, 62.

36 En lugar del "ideal cristiano de responsabilidad moral según el cual la acción individual es un producto de la voluntad libre del individuo", la responsabilidad genuina para Nietzsche "tiene lugar cuando son superados puntos de vista (necesidades) como la creencia cristiana en el libre albedrío. La responsabilidad en el individuo soberano es prometedora porque es amoral más que moral; inconsciente más que consciente; instintiva más que reflexiva; necesaria más que libre; una forma del olvido más que de la memoria" (Lemm, 2010, 96). Más aún, la idea de responsabilidad moral no es inocente, sino más bien el veneno del instinto de venganza como agresividad interiorizada bajo la forma de mala conciencia (cf. Reboul, 1993, 92). Por ello, Nietzsche afirma que, desde un punto de vista físiológico, "en la lucha contra la bestia el ponerla enferma puede ser el único medio de debilitarla" (CI, Los “mejoradores" de la humanidad, 2/Nietzsche, 2002, 79).

37 CI, 38/Nietzsche, 2002, 121.

38 CI, 38/Nietzsche, 2002, 122.

39 Véase Lemm, 2010, 84. 
La expresión "libertad de la voluntad" (Freiheit des Willens) designa, por tanto, el complejo estado placentero del volente (vielfachen Lust-Zustand des Wollenden), el cual manda y al mismo tiempo se identifica con el ejecutor. La volición es en realidad el resultado de las relaciones de dominio en el alma en cuanto ésta es concebida como colectividad y jerarquía social. El cuerpo y el alma así interpretados se asemejan a una sociedad aristocrática ${ }^{40}$. Y, como en toda comunidad bien regida, es la clase gobernante la que se atribuye el éxito del buen resultado del acto volitivo colectivo que ella pretende conducir. Por eso dice Nietzsche que "la doctrina de la libertad de la voluntad es una invención de las clases dominantes"41. La volición es, por tanto, el feliz resultado de la acción conjunta de las distintas fuerzas que constituyen el cuerpo social en el que, como sucede en un buen ejército, existe una correspondencia recíproca entre mando firme y decidido y obediencia resuelta y diligente por parte de los subordinados ${ }^{42}$. Por consiguiente, "lo que se llama «libertad de la voluntad» es esencialmente -afirma Nietzsche- el afecto de superioridad [Überlegenheits-Affekt] con respecto a quien tiene que obedecer: «yo soy libre, 'él' tiene que obedecer»" 43 .

Por tanto, creencias como que la voluntad es una unidad simple y que es la causa en general, que hay algo así como el yo-substancia o que existe la libertad cristiana de la voluntad se revelan, a la postre, simplemente como ídolos engendrados por el culto inconsciente a la gramática del lenguaje. Nietzsche pretende desenmascarar estas ideas como meros mitos y desvelar, desde una perspectiva genealógica, el fondo inconsciente del que surgen. Así, "lo que unitariamente llamamos «cuerpo» en el nivel de la conciencia, no es más que una ficción que designa una simplificación, una reducción lógica y abstracta que lo convierte en un mero concepto" 4 . En este sentido, como sostiene Jara, el cuerpo vendría a ser "la sede en que se articula esa pluralidad de fuerzas que luego han sido interpretadas simplificada y unitariamente con los nombres de sujeto, alma y voluntad"45.

En consecuencia, la pretensión de que hay un yo uno, simple y autónomo que es la causa y el dueño de sus pensamientos y voliciones, así como que éstas surgen a voluntad de ese yo amo de sí y de sus actos, no es más que superstición. La gramática ha jugado una mala pasada a los filósofos que, cegados por sus prejuicios, han querido ver unidad y simplicidad

40 Inspirado por Nietzsche, Ortega sustenta una interpretación radicalmente aristocrática de la historia y de la sociedad (no el Estado), que revela el sello del filósofo teutón. Según Ortega, no se trata de si la sociedad humana debe ser aristocrática, sino que "la sociedad humana es aristocrática siempre, quiera o no, por su esencia misma, hasta el punto de que es sociedad en la medida en que sea aristocrática, y deja de serlo en la medida en que se desaristocratice" (Ortega y Gasset, 2008, 135). La cuestión de quién ha de detentar el mando y el dominio en el cuerpo social, como en el cuerpo orgánico individual para Nietzsche, es, por lo tanto, de primera importancia. De hecho, la segunda parte de La rebelión de las masas se titula precisamente "¿Quién manda en el mundo?". Según Ortega, mando significa “poder espiritual” (Ortega y Gasset, 2008, 275). Por ello, "sin un poder espiritual, sin alguien que mande, y en la medida que ello falte, reina en la humanidad el caos" (Ortega y Gasset, 2008, 276).

41 El caminante y su sombra, 9/Nietzsche, 2010, 166.

42 Según Canetti, el ejército es el símbolo de masa de la nación alemana unificada, constituida tras la guerra franco-prusiana de 1870-1871. Canetti afirma que aquella guerra impulsó inicialmente a Nietzsche a escribir su obra La voluntad de poder, lo cual muestra "hasta qué punto la importancia del ejército para los alemanes era un fenómeno colectivo, cómo este símbolo de masa ejercía su influencia incluso entre aquellos que sabían distanciarse altivamente de todo cuanto recordara a las multitudes" (Canetti, 2014, 287).

43 MBM, § 19/Nietzsche, 2008b, 42.

44 Sánchez Meca, 2009, 125.

45 Jara, 1998, 188. 
reales donde sólo hay unidad nominal. Nietzsche, denunciando el mito del yo, ha desmembrado el sujeto antaño unitario en un campo de fuerzas, en virtud de lo cual la subjetividad ha pasado a ser concebida como pluralidad. Para él, como advierte D'Agostini, "el sujeto es una ficción, un simulacro o una «máscara» que no cubre ninguna verdad última" ${ }^{46}$. Nietzsche reinterpreta, de este modo, el sujeto como "un conjunto de «máscaras» inventadas cada vez por la voluntad de poder para hacer el yo plausible a sí mismo y a los otros, y bajo cada máscara (como bajo cada filosofía) aparece otra nueva en un juego infinito" 47 . Como resultado de ello, el honesto y viejo yo (das ehrliche alte Ich) se ha volatilizado, viéndose reducido a un pequeño y escurridizo "ello"48. Esta disolución del sujeto cartesiano y trascendental está asociada en Nietzsche, por tanto, a una revalorización sustantiva del cuerpo como auténtico "sí-mismo" dotado de una pluralidad dinámica. Este punto de vista ha tenido, a la postre, una enorme influencia en el pensamiento contemporáneo como pone de relieve la idea de la "muerte del hombre" o la del "fin del sujeto" 49 .

\section{A modo de conclusión}

Nietzsche restituye el cuerpo al puesto principal que, de acuerdo con su punto de vista genealógico del valor, le corresponde ocupar, situándolo, como hemos visto, en una posición filosófica central. Nietzsche pone de manifiesto que la estructura realmente decisiva y esclarecedora en el cuerpo es la dominación, en la medida en que su carácter distintivo y definitorio viene determinado por el antagonismo de los impulsos que buscan incesantemente mandar y someter para convertirse en instancia valorativa suprema. Este impulso de dominación se refleja también en las doctrinas de los filósofos, que se hallan fuertemente condicionadas, pese a que se pretenda lo contrario, por los instintos predominantes en el pensador. Desde su perspectiva genealógica, Nietzsche sostiene que es el cuerpo, aunque se haya querido otra cosa, el que ha creado el espíritu como instrumento al servicio de sus fines inconscientes. Por tal motivo, el espíritu debería interpretarse como expresión cifrada del cuerpo. En suma, Nietzsche se propone mostrar, desde este punto de vista, que el cuerpo -con su inteligencia y sabiduría superiores de carácter inconsciente, "prelógico" y "prerracional"- ha de ocupar el lugar de aquellas ficciones filosóficas que, como el yo, la conciencia o la voluntad libre, han sido finalmente desenmascaradas, revelándose, a la postre, simplemente como mitologías. En este sentido, Nietzsche ha sido uno de los principales inspiradores e impulsores de la disolución del sujeto que ha tenido lugar en el pasado siglo y de la que aún somos testigos.

46 D'Agostini, 2010, 135.

47 D'Agostini, 2010, 112-113.

48 MBM, § 17/Nietzsche, 2008b, 40.

49 Según Trías, la idea de la "muerte del hombre", planteada por Foucault, significa que "el «hombre» o el «sujeto humano» constituyen fetiches. Que el humanismo, el subjetivismo, el personalismo, el existencialismo, han abonado un cierto fetichismo: fijar un papel social, una máscara o disfraz como patrón de una pretendida identidad o self. La muerte del hombre significa, por tanto: la disolución de esa identidad y la liberación de una profusión de máscaras o disfraces que todos nosotros almacenamos -y que inhibimos en virtud de ese fetichismo" (Trías, 1984, 14-15). 


\section{Referencias bibliográficas}

Conill Sancho, J. (2007), El poder de la mentira: Nietzsche y la política de la transvaloración (tercera edición), Madrid: Editorial Tecnos.

D’Agostini, F. (2010), Analíticos y continentales. Guía de la filosofía de los últimos treinta años, Madrid: Ediciones Cátedra.

Canetti, E. (2014), Masa y poder (Obra completa 1), traducción y edición de Juan José del Solar, Barcelona: Debolsillo.

Deleuze, G. (1989), El pliegue, traducción de José Vázquez y Umbetina Larraceleta, Barcelona: Ediciones Paidós Ibérica.

Deleuze, G. (1986), Nietzsche y la filosofía, traducción de Carmen Artal, Barcelona: Editorial Anagrama.

Heidegger, M. (2013), Nietzsche, traducción de Juan Luis Bermal, Barcelona: Editorial Planeta.

Heidegger, M. (1975), Die Frage nach dem Ding, Tubinga: Max Niemeyer Verlag.

Husserl, E. (1992), Cartesianische Meditationen, en Gesammelte Schriften (Band 8), editado por Elisabeth Stroker (Text nach Husserliana VI), Hamburgo: Felix Meiner Verlag.

Jara, J. (1998), Nietzsche, un pensador póstumo: El cuerpo como centro de gravedad, Barcelona/Chile: Anthropos Editorial/Universidad de Valparaíso.

Leibniz, G. W. (1977), Nuevos ensayos sobre el entendimiento humano, edición preparada por J. Echeverría, Madrid: Editora Nacional.

Lemm, V. (2010), La filosofía animal de Nietzsche: Cultura, política y animalidad del ser humano, traducción de Diego Rossello, Santiago de Chile: Ediciones Universidad Diego Portales.

Nietzsche, F. (2010), El nacimiento de la tragedia/El caminante y su sombra/La ciencia jovial, estudio introductorio de Germán Cano (traducción de El nacimiento de la tragedia y La ciencia jovial de Germán Cano. Traducción de El caminante y su sombra de Alfredo Brotons), Madrid: Editorial Gredos.

Nietzsche, F. (2008a), Así habló Zaratustra: un libro para todos y para nadie, introducción, traducción y notas de Andrés Sánchez Pascual, Madrid: Alianza Editorial.

Nietzsche, F. (2008b), Más allá del bien y del mal. Preludio de una filosofía del futuro, Introducción, traducción y notas de Andrés Sánchez Pascual, Madrid: Alianza Editorial.

Nietzsche, F. (2002), El crepúsculo de los ídolos o cómo se filosofa con el martillo, introducción, traducción y notas de Andrés Sánchez Pascual, Madrid: Alianza Editorial.

Nietzsche, F. (1998), La genealogía de la moral, introducción, traducción y notas de Andrés Sánchez Pascual, Madrid: Alianza Editorial.

Ortega y Gasset, J. (2013), El hombre y la gente (décima reimpresión), Madrid: Alianza Editorial.

Ortega y Gasset, J. (2008), La rebelión de las masas (segunda edición), edición de Domingo Hernández Sánchez, Madrid: Editorial Tecnos.

Reboul, O. (1993), Nietzsche, crítico de Kant, traducción de Julio Quesada y José Lasaga, Barcelona: Editorial Anthropos.

Sánchez Meca, D. (2009), Nietzsche: la experiencia dionisiaca del mundo (cuarta edición), Madrid: Editorial Tecnos. 
Sánchez Meca, D. (2002), «Psicofisiología nietzscheana del arte y de la decadencia», en: J. Rivera de Rosales y M. López Sáenz (coord.): El cuerpo. Perspectivas filosóficas, Madrid: UNED, pp. 107-132.

Schaeffer, J.-M. (2009), El fin de la excepción humana, traducción de Elisenda Julibert, Barcelona: Marbot Ediciones.

Schopenhauer, A. (2010), El mundo como voluntad y representación (2 vols.), traducción Roberto R. Aramayo, Madrid: Alianza Editorial.

Spinoza, B. (2014), Ética demostrada según el orden geométrico, traducción de Oscar Cohan, estudio preliminar de Luciano Espinosa, Madrid: Editorial Gredos/RBA.

Trías, E. (1984), Filosofía y carnaval y otros textos afines (tercera edición ampliada), Barcelona: Editorial Anagrama. 